\title{
Influence of Applied Voltage on Surface Morphology and Wettability of Biological Coatings on Ti6-Al-4V by Micro-Arc Oxidation Treatment
}

\author{
Yajie Chu ${ }^{a, b^{*}}$, Peng Liu' ${ }^{(D)}$, Yixin Chen ${ }^{a}$, Xiaoquan Li $^{a, b}$ \\ ${ }^{a}$ Department of material engineering, Nanjing Institute of technology, Nanjing 211167, China \\ ${ }^{b}$ Jiangsu Key Laboratory of Advanced Structure Materials and Application Technology, \\ Nanjing, 211167 China \\ ${ }^{c}$ School of Materials Science and Engineering, Shandong Jianzhu University, Jinan 250101, China
}

Received: January 6, 2020; Accepted: March 17, 2020

\begin{abstract}
Micro-arc oxidation (MAO) treatment with various voltages was carried out on Ti alloys in $10 \% \mathrm{H}_{2} \mathrm{SO}_{4}$ aqueous solution to enhance surface wettability for biological application. The effects of applied voltage on the surface morphology, phase constituents, functional group, roughness and wettability of the MAO coatings were investigated comprehensively. Increasing applied voltages significantly change phase constituents, surface morphology and wettability of the MAO coatings. Higher applied voltages are favorable to form higher fraction of rutile phase, larger micro-pores and higher surface roughness. The apparent contact angle decreases slightly after treated at $80 \mathrm{~V}$ but it decreases sharply after treated at $160 \mathrm{~V}$ or $200 \mathrm{~V}$. The significant change in wettability of MAO coatings is attributed to hydroxyl group content and morphology of the MAO coatings. Differences in hydroxyl group content and surface morphology result in different contact interface types between water and MAO coatings, which is attributed to air captured or no air captured interface models.
\end{abstract}

Keywords: Microarc oxidation, oxide film morphology, roughness, wettability, biomedical applications.

\section{Introduction}

Titanium and its alloys have become an excellent material for orthopedic and dental implants due to their excellent biocompatibility, mechanical properties, manufacture ability and nonmagnetic character ${ }^{1-3}$. However, titanium as a bioinert material neither chemically connects to bone nor actively induces new bone growth by itself, which result in a weak bonding between titanium implants with human tissues and a long healing time after the implantation. Various surface modification methods have been tried on titanium implants to improve its biological performance. Previous literature shows that the biological response of tissues and cells to implant depends on its surface characters, such as surface morphology, roughness, functional group and wettability. Micro-rough surface on the implant can lead to better osseointegration and higher removal torque values, which is helpful for implant ${ }^{4-6}$. On the other hand, surface wettability of implant influences the cell-material interactions, and hydrophilic surfaces induce greater osteoblastic cell growth and mineral deposition compared with hydrophobic surfaces ${ }^{7,8}$.

Among the surface modification methods that are used on Ti implant to improve its biological performance ${ }^{9,10}$, micro-arc oxidation (MAO) has been paid considerable attention because of its advantages, such as the capability to prepare porous structure through the discharging effect of high voltage and the capability to introduce some helpful elements (Ca, $\mathrm{P}$ and $\mathrm{F}$ ) for its biological performance into the titanium oxide films ${ }^{11,12}$. It is well known that the prepared MAO

*e-mail: chuyajie@njit.edu.cn coating properties are mainly dependent on the used electrolyte components and electrical parameters. Yang et al. ${ }^{13}$ reported that $\mathrm{H}_{2} \mathrm{SO}_{4}$ is an effective electrolyte to prepare bioactive titanium metal, which is suitable for the applications under the loading-bearing conditions. Cui et al. ${ }^{14}$ studied the phase composition and apatite formation ability of the MAO films treated with a $\mathrm{H}_{2} \mathrm{SO}_{4}$ electrolyte. Porous MAO films mainly consist of rutile or rutile/anatase phases. Compared with anatase, rutile in MAO film is more effective to induce the apatite deposition/formation, thereby improving the biological performance. Many applied processing parameters during MAO treatment, such as voltage, impulse frequency, current density, pulse duration time and duty ratio on the plasma characteristics, would influence the surface morphology and composition of the oxide film ${ }^{15-17}$. It has been reported that the voltage among many parameters applied in MAO treatment considerably affects the oxide film surface characters including composition, morphology and phase $\mathrm{e}^{18,19}$.

The aim of this work is to investigate the effects of applied voltage on the surface morphology, phase constituents, roughness and wettability of the MAO coatings for biological implant application.

\section{Materials and Methods}

\subsection{Materials and MAO treatments}

Commercial medical Ti-6Al-4V plates with dimension of $15 \times 30 \times 1.5 \mathrm{~mm}^{3}$ were used in this work. Samples were abraded with 400 -grit $\mathrm{SiC}$ paper, and then they were 
rinsed using a mixture of nitric acids and hydrofluoric acid (3:1 in volume fraction). Finally, they were washed with acetone in an ultrasonic cleaner.

MAO treatment was performed on a power with rectangular pulses supply. Electrolyte was used 10\% $\mathrm{H}_{2} \mathrm{SO}_{4}$ aqueous solution. The electrolyte container was a box made of stainless steel. MAO treatment was performed at a $30 \mathrm{~kW}$ pulsed DC power, which could be operated with constant voltage, constant current or constant power mode. Schematic diagram of MAO treatment in this work is shown in Figure 1a. The schematic diagram of the output pulse for MAO supply in pulsed DC model is shown in Figure 1b, in which $U_{\mathrm{c}}$ and $U_{\mathrm{a}}$ are the cathodic and anodic voltage, respectively. $T_{\mathrm{c}}$ and $T_{\mathrm{a}}$ are the cathodic and anodic impulse periods, respectively. $T c^{\text {on }}$ and $T a^{\text {on }}$ are the cathodic and anodic impulse widths, respectively. $T c^{\text {off }}$ and $T a^{\text {off }}$ are the cathodic and anodic intra pulses, respectively. The parameters used in MAO process are listed in Table 1.

The electrolyte was cooled by a cooling system during this treatment, and its temperature during MAO process was kept from $40{ }^{\circ} \mathrm{C}$ to $60^{\circ} \mathrm{C}$. The MAO samples were treated for $20 \mathrm{~min}$. The equivalent current during MAO process was recorded instantaneously. After MAO treatment, the samples were washed with deionized water. Finally, the MAO samples were dried at $180^{\circ} \mathrm{C}$ for $2 \mathrm{~h}$ in a drying box.

\subsection{Characterizations of MAO coatings}

The MAO films morphology was observed by scanning electron microscopy (SEM, FEI Quatan 450, America) equipped with energy dispersive $\mathrm{x}$-ray analysis (EDAX). The MAO films thickness of the samples was also measured with SEM. The phase component of the MAO films was analyzed by X-ray diffraction (XRD, D8-Advanced; Bruker, Germany) with $\mathrm{Cu} \mathrm{\textrm {K } _ { \alpha }}$ radiation at $4.0^{\circ} / \mathrm{min}$ scanning speed and using scanning range $(2 \theta)$ from $20^{\circ}$ to $60^{\circ}$. Fourier transform infrared spectroscopy (FTIR, SPECTRUM 100, America) was used to analyze the functional groups component of the MAO coatings. In the FTIR experiment, the resolution and scanning range were $4 \mathrm{~cm}^{-1}$ and $4500-400 \mathrm{~cm}^{-1}$ respectively.
The Ra value of the MAO coatings was measured by a surface rough meter (Talysurfi 200), at a measure speed of $0.5 \mathrm{~mm} / \mathrm{s}$ and tange/tesolution of $\pm 1 \mathrm{~mm} / 0.008 \mu \mathrm{m}$. The static water contact angle of the MAO coatings at ambient temperature was measured by an optical contact angle meter (JC2000A) equipped with a computer-controlled liquid dispensing system. In the contact angle measurements, considering the possible significant variation of contact angle in the early test stage, the contact angles were measured and recorded after $30 \mathrm{~s}$ since the drops fell onto solid surface. An average contact angle value from four measurements was reported for each treated surface.

\section{Results and Discussion}

\subsection{XRD and FTIR analysis of the MAO coatings}

Figure 2 shows the XRD patterns of the MAO coatings prepared at different anode voltages. As shown in Figure 2, the MAO film prepared at $80 \mathrm{~V}$ consists of $\alpha$-Ti phase and anatase, and no significant rutile peaks is identified in the patterns. The MAO films prepared at $120 \mathrm{~V}, 160 \mathrm{~V}$ and $200 \mathrm{~V}$ are composed of anatase and rutile besides $\alpha$-Ti phase. However, the peaks of rutile prepared at $160 \mathrm{~V}$ and $200 \mathrm{~V}$ are more significant compared to $120 \mathrm{~V}$, which indicates that the faction ratio of rutile increases in the MAO coatings. These results are in accordance with those reported by $\mathrm{Cui}^{20}$. Cui reported that the MAO coatings of titanium substrate consist of anatase phase after treated at lower voltages (i.e $100 \mathrm{~V}$ ), anatase and rutile phases at medium voltages (i.e $150 \mathrm{~V}$ ), but only rutile phase at higher voltages (i.e $180 \mathrm{~V}$ ). However, the peaks of $\alpha$-Ti obtained in this work may come from Ti substrate, which is attributed to the porous characteristics of the MAO films. This current work and the work by Cui show that higher voltage tends to form rutile.

Figure 3 shows the FTIR spectroscopy of the MAO coatings prepared with various applied voltages. As seen from the Figure 3, the wide region from $900 \mathrm{~cm}^{-1}$ to $600 \mathrm{~cm}^{-1}$ is an absorption band of $\mathrm{TiO}_{2}$. The absorption bands from $3700 \mathrm{~cm}^{-1}$ to $3400 \mathrm{~cm}^{-1}$ and $1720 \mathrm{~cm}^{-1}$ are $\mathrm{OH}$ characteristic band. According to previous

Table 1. Parameters applied in the MAO treatments.

\begin{tabular}{ccccc}
\hline Anodic voltage & Anodic load & Cathodic voltage & Cathodic load & Frequency \\
\hline $80 \sim 200 \mathrm{~V}$ & $15 \%$ & $15 \mathrm{~V}$ & $10 \%$ & Time \\
\hline
\end{tabular}

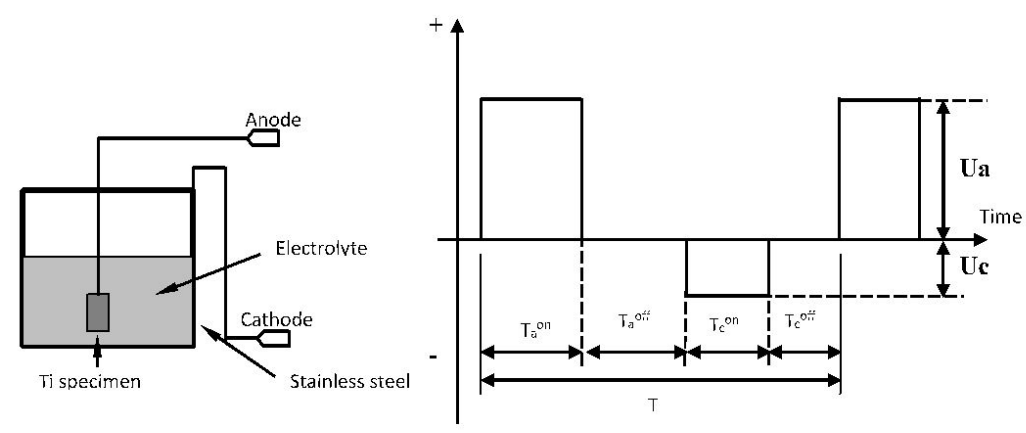

(a) Schematic of microarc oxidation step

(b) Pulse parameters applied in pulsed DC supply

Figure 1. (a) Schematic of microarc oxidation step, (b) Pulse parameters applied in pulsed DC supply 


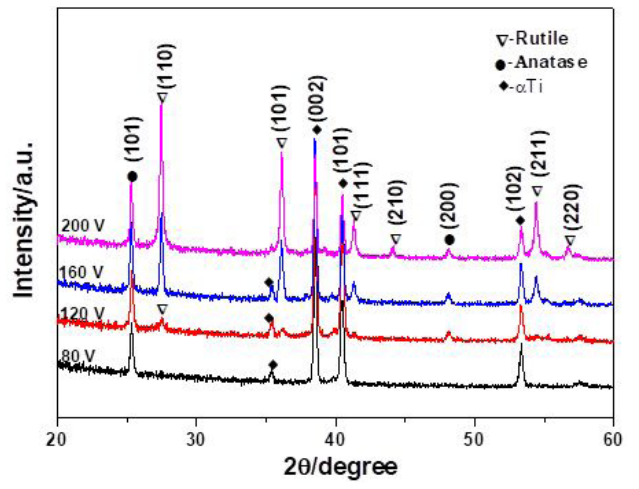

Figure 2. XRD patterns of the MAO coatings applied various voltages.

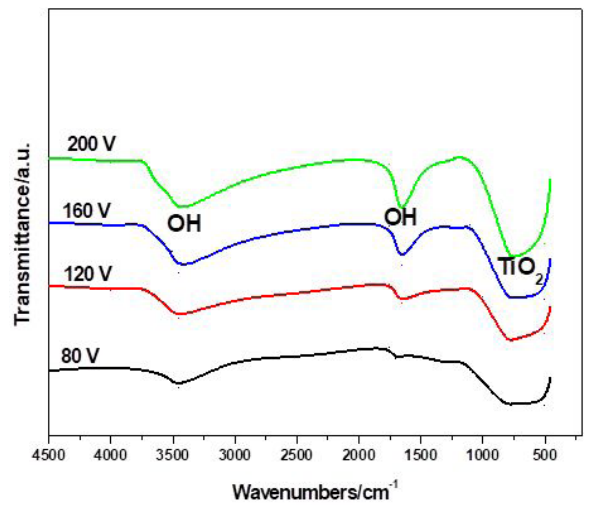

Figure 3. FTIR of the MAO coating prepared at various voltages. reports, $\mathrm{OH}$ formation is attributed to the dissociation effect of $\mathrm{TiO}_{2}$ to $\mathrm{H}_{2} \mathrm{O}$. Jones and Hockey ${ }^{21}$ reported two absorption bands of $\mathrm{OH}$ at $3715 \mathrm{~cm}^{-1}$ and $3675 \mathrm{~cm}^{-1}$ on anatase phase and one $\mathrm{OH}$ absorption band formed on rutile phase at $3680 \mathrm{~cm}^{-1}$. Primet et al. ${ }^{22}$ showed that these two $\mathrm{OH}$ absorption bands of anatase phase were at $3715 \mathrm{~cm}^{-1}$ and $3665 \mathrm{~cm}^{-1}$, but three $\mathrm{OH}$ absorption bands of rutile were observed at 3685,3655 and $3410 \mathrm{~cm}^{-1}$. It also can be seen from Figure 3 that the absorption bands of $\mathrm{OH}$ become stronger with the increase of applied voltage. It can be deduced that higher applied voltages is favorable for the formation of $\mathrm{OH}$ groups during MAO treatment.

\subsection{Morphology and roughness of the MAO films}

Figure 4 and Figure 5 shows the morphology of the MAO coatings on surface and intersecting surface after treated with various applied voltages. The MAO coatings present a porous structure formed by the discharging tunnel of micro-arc. Many micro-pores in various sizes are distributed on the MAO films because of the heterogeneity of discharging. Meanwhile, some micro-cracks can be observed on the MAO coatings. The formation of micro-cracks may result from the thermal stress caused by high temperature due to the discharging effect in MAO process. On the other hand, the diameter of micro pores is greatly associated with the applied voltage. With the applied voltage increasing from $80 \mathrm{~V}$ to $200 \mathrm{~V}$, the maximum diameter of micro pores increases from about $1 \mu \mathrm{m}$ to $5 \mu \mathrm{m}$. The effect of applied voltage on MAO coating morphology may be attributed to

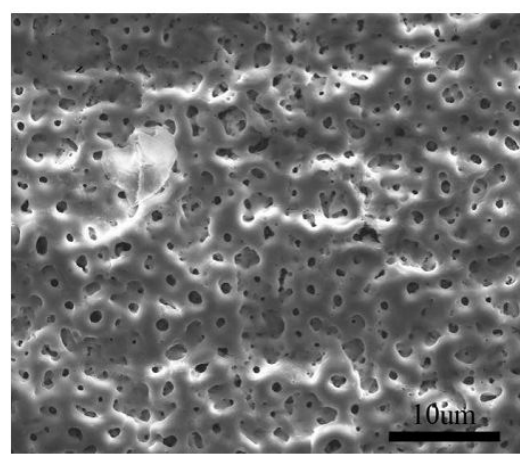

(a) $80 \mathrm{~V}$

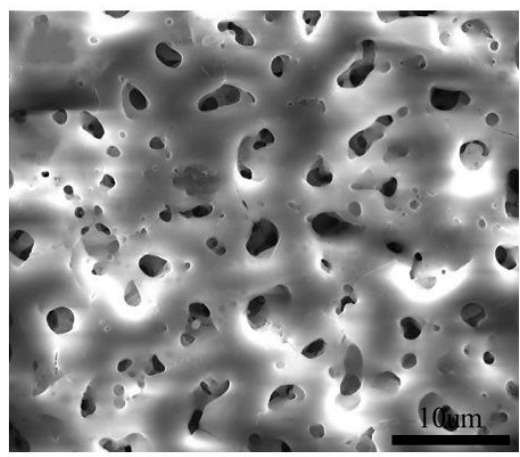

(c) $160 \mathrm{~V}$

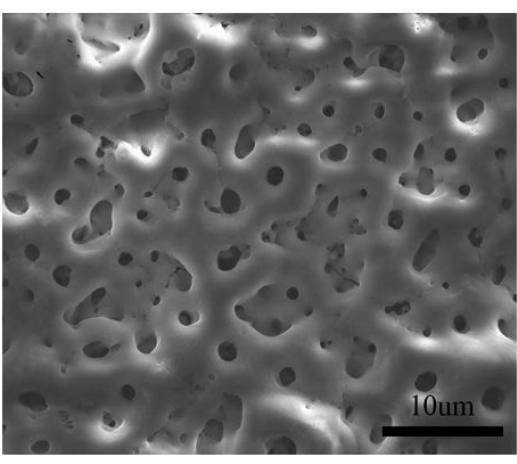

(b) $120 \mathrm{~V}$

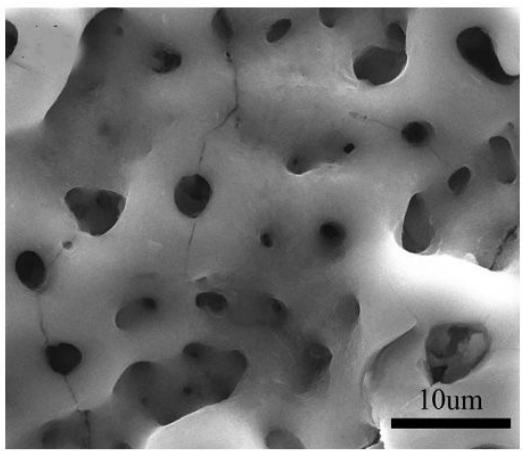

(d) $200 \mathrm{~V}$

Figure 4. SEM of the MAO coating surface at several voltages: (a) $80 \mathrm{~V}$, (b) $120 \mathrm{~V}$, (c) $160 \mathrm{~V}$, (d) $200 \mathrm{~V}$. 


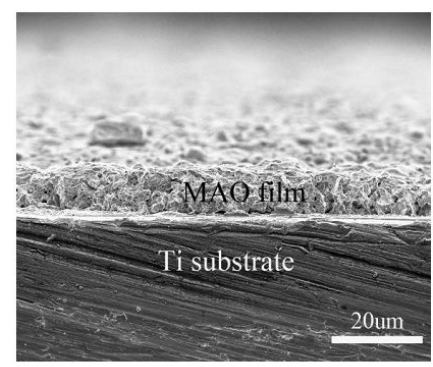

(a) $80 \mathrm{~V}$

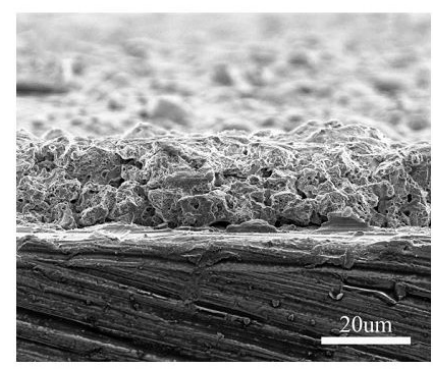

(c) $160 \mathrm{~V}$

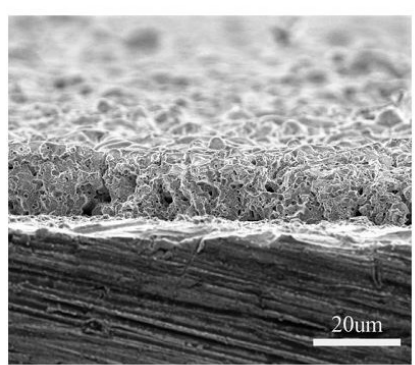

(b) $120 \mathrm{~V}$

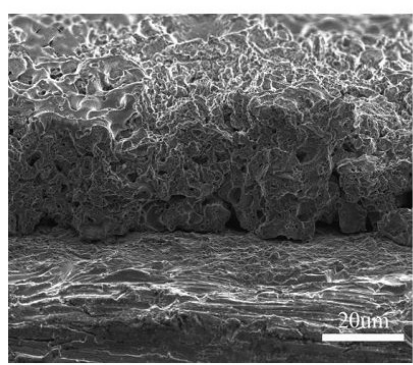

(d) $200 \mathrm{~V}$

Figure 5. SEM of the MAO coating intersecting surface, for various voltages (a) $80 \mathrm{~V}$, (b) $120 \mathrm{~V}$, (c) $160 \mathrm{~V}$, (d) $200 \mathrm{~V}$.

the discharging energy during MAO treatment, which will be discussed further.

Figure 6 shows the value of Ra of the MAO films treated with various voltages. The roughness of the samples increases after MAO treatment. When the applied voltage increases from $80 \mathrm{~V}$ to $200 \mathrm{~V}$, the roughness of the MAO films increases slightly. The influences of MAO treatment on surface roughness of samples may be analyzed from two reversed effects of MAO discharging. Micro-peaks on Ti surface are easy to discharge due to the tip discharge effect, and then the melts fill the micro-valleys, which decrease the difference in height between the micro-peaks and micro-valleys thereby decreasing $\mathrm{Ra}$. As such, the original profile of $\mathrm{Ti}$ surface can be changed totally by MAO treatment after a certain period of time. The final profile depends on the MAO treatment conditions, such as applied voltages and current density. In this case, rougher surface is attributed to the stronger discharging effect under higher applied voltages.

Morphology and roughness of the MAO films are interpreted with a single pulse model. The single pulse discharging energy in this model is described by the following equation ${ }^{23}$ :

$$
E=\int_{0}^{T} U(t) I(t) d t
$$

where $\mathrm{E}, \mathrm{U}(\mathrm{t})$, T and $\mathrm{I}(\mathrm{t})$ represent the impulse discharging energy, impulse voltage, impulse period and impulse current, respectively. According to the single pulse model, the growth of MAO coating mainly occurs in the positive impulse performed period, and the formation and properties of the MAO coating is mainly dependent on the energy of a single pulse. The energy of a single pulse can be expressed as following:

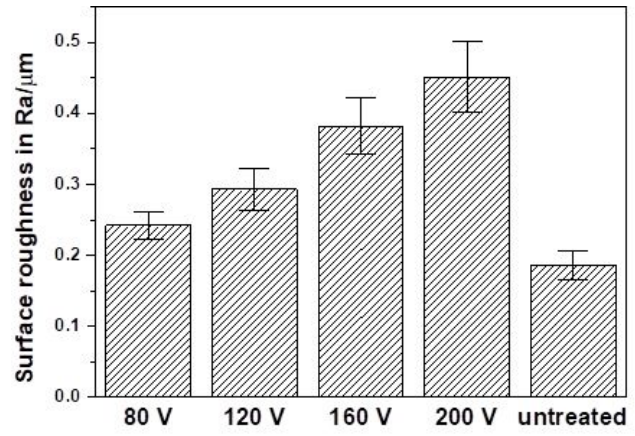

Figure 6. Surface roughness of the samples untreated and subjected to MAO treatment applied various voltages.

$$
E \approx \int_{0}^{T a} U a(t) I a(t) d t
$$

Where $\mathrm{E}, \mathrm{Ua}(\mathrm{t})$, Ta and $\mathrm{Ia}(\mathrm{t})$ are the pulse energy, anodic pulse voltage, anodic pulse performed period and anodic pulse current, respectively. In the formation of MAO coating, mainly during anodic voltage performed stage, regardless of the stability of the discharge process or the quantity of micro-discharge, the change in the anodic voltage is very small and it can almost be neglected ${ }^{24}$. Therefore, in Equation 2, the anodic impulse voltage $\mathrm{Ua}(\mathrm{t})$ is a constant, which is used $80 \mathrm{~V}, 120 \mathrm{~V}, 160 \mathrm{~V}, 200 \mathrm{~V}$, respectively. Then, the single pulse energy with the pulsed DC power supply can be expressed approximately as following:

$$
E=U a \int_{0}^{T a} I a(t) d t
$$

In this work, equivalent current $(I e(t))$ is used, which is defined as the average current during total duration time of the single pulse. According to this definition: 


$$
E=U a \int_{0}^{T} \operatorname{Ie}(t) d t
$$

From Equation 3 and 4, Ie $(t)=I a(t) \cdot D a$, where $D a$ is $\mathrm{Ta}^{\text {on }} / \mathrm{T}$ presented in Figure 1. As such, the single pulse energy is proportional to the equivalent current and anodic pulse voltage. The equivalent currents were recorded in this work, as presented in Figure 7, which is also proportional to the applied anodic pulse voltage approximately. In the initial stage, the equivalent current density drops sharply, and then, the equivalent current density decreases gradually with the increase of time. Compared with the discharging of the surface of Ti substrate to electrolyte directly, the discharging of the interface of $\mathrm{Ti}$ substrate/MAO film to electrolyte is more difficult because of the blocking effect of the oxide films ${ }^{25,26}$. The growth of MAO film resulted in the decreasing of the equivalent current during MAO treatment.

Based on the Equation 4, the single pulse energy of MAO treatment has a power relation with the applied voltage under same conditions. Figure 8 shows the thickness of the MAO coatings as a function of the anodic voltage. According to Figure 8 , the thickness of the MAO coating also shows a power relation with the applied anodic voltage. Wei et al. has also reported a same power relation with the MAO coating thickness with the applied anodic voltage, which may result from the relation between the discharging energy with the applied voltage during MAO coating formation.

\subsection{Wettability measured with contact angle of the MAO films}

Contact angle is an important measurement method to evaluate material surface wettability, and materials with better wettability present lower contact angles. Figure 9 show the contact angles tested the MAO coatings prepared at various applied anodic voltages. The contact angle of the sample decreases dramatically after MAO treatment with the applied voltage increased from 80 to $200 \mathrm{~V}$. As discussed in above, the $\mathrm{OH}$ content and morphology of these MAO films are different after treated at various voltages. Lin et. al investigated the effect of oxygen concentration in $\mathrm{TiOx}$ films on the formed phases, crystallinity and wettability. Their results showed that the contact angle of $\mathrm{TiOx}$ film varied from about $70^{\circ}$ to $30^{\circ}$, and the wettability is mainly determined by phases and surface roughness. As such, the sharp variation of contact angle at applied voltage may result from multiple influencing factor including roughness, morphology and $\mathrm{OH}$ content.

Therefore, two models reported in the literature are used to explain the sharp variation in apparent contact angle obtained in the present work. For the MAO coatings with smaller pores, roughness and lower content of $\mathrm{OH}$ prepared at lower applied voltages, water cannot wet the smaller pores of the MAO coating surface, which forms a water/MAO coating interface presented in Figure 10a, In other words, such a morphology and water surface tension lead to the capture of ambient gas in the interface between the MAO coating surface and water used for the contact angle test. The Cassie-Baxter equation can be used to evaluate the apparent contact angle of the heterogeneous surface of the MAO coatings ${ }^{27,28}$ :

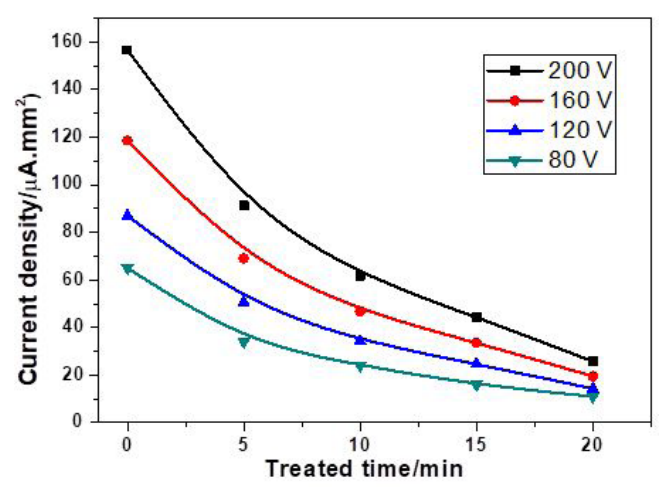

Figure 7. Equivalent current density as a function of treated time during MAO treatment.

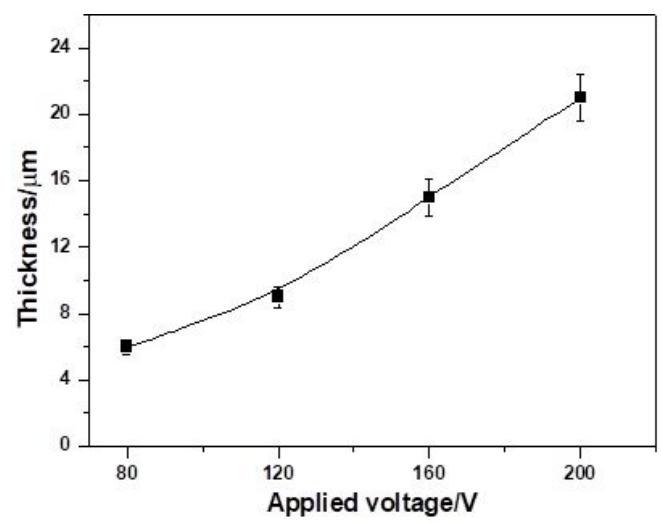

Figure 8. Thickness of the MAO films as a function of applied voltage.

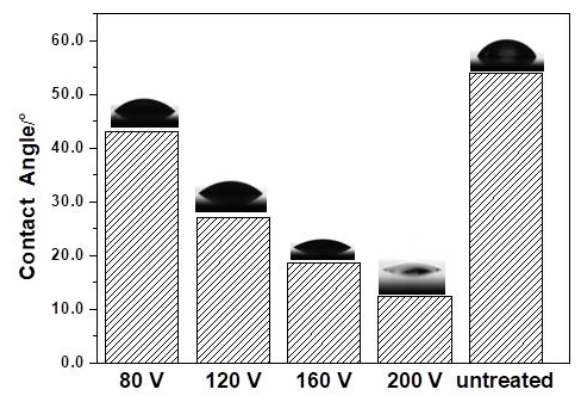

Figure 9. Contact angle of the samples untreated and subjected to MAO treatment applied various voltages.

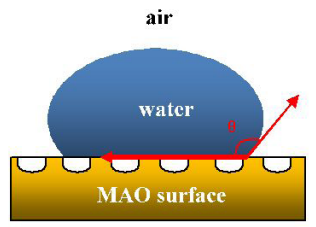

(a) ambient gas is trapped in valleys of MAO coating surface

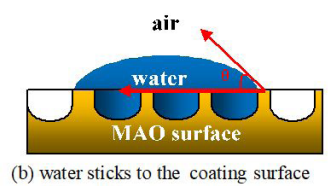

Figure 10. Two interface models used to describe the contact angle of the MAO coatings prepared at various voltages (a) ambient gas is trapped in valleys of MAO coating surface. (b) water sticks to the coating surface. 
$\cos \left(\theta_{A}\right)=f_{w} \cdot\left(1+\cos \left(\theta_{i}\right)\right)-1$

Where $\theta_{A}$ is an apparent contact angle, $f_{w}$ is the fraction of solid surface area wet by the liquid, and $\theta_{i}$ is the contact angle corresponding to the ideal surface. Based on Equation 5, it can be deduced that the wettability is under-estimated by the apparent contact angle with the decrease of $f_{w}$.

For the MAO coatings prepared at higher applied voltages form larger pores, roughness and higher content of $\mathrm{OH}$, which promote the absorption of water on the MAO surface. These effects of surface morphology and $\mathrm{OH}$ content on contact angle can be evaluated by Wenzel's model ${ }^{29}$, as presented in Figure 10b. In this model, water drop sticks to the MAO coating surface, when the area value of interface of the liquid/solid increases, the apparent contact angle decreases. Wenzel has also established a quantitative relation between the apparent contact angles with the surface roughness to describe the decrease of the apparent contact angle with surface roughness:

$$
\cos \left(\theta_{A}\right)=r \cdot \cos \left(\theta_{i}\right)
$$

Where $\mathrm{r}$ is the ratio of the MAO coatings real surface area to its projected perfectly smooth surface, i.e. $r$ is a parameter used to characterize the extension of surface area of the MAO coatings due to the micro pores and surface roughness. In Equation 6, $\mathrm{r}=1$ for perfectly smooth surface. Therefore, $\cos \left(\theta_{A}\right)=\cos \left(\theta_{i}\right)$, where $\theta_{i}$ is the contact angle corresponding to the ideal surface. In practice, Wenzel's model is used for the contact angle range $0^{\circ}<\theta<90^{\circ}$. According to this theory, increasing the surface roughness $(r>1)$ leads to the decrease in apparent contact angle compared to the contact angle corresponding to the ideal surface. Furthermore, due to the many micro pores formed on the MAO coatings at higher voltages, the value of $r$ in Equation 6 is not proportional any more to that of Ra measured in this work. It can be deduced that the actual effect of roughness and morphology on the contact angle of the MAO coatings is greatly greater than the effect of single Ra because of many micro-pores.

\section{Conclusions}

Micro-arc oxidation (MAO) treatment at various voltages was carried out on Ti alloys in $10 \% \mathrm{H}_{2} \mathrm{SO}_{4}$ aqueous solution to enhance surface wettability. The effects of applied voltage on the surface morphology, phase ratio, $\mathrm{OH}$ content, roughness and wettability of the MAO coatings were investigated. Some conclusions can be drawn from this work.

1. The MAO coatings prepared at various applied voltages present different rutile /anatase ratio, hydroxyl group content and surface morphology. Higher applied voltages are favorable to form higher fraction of rutile phase, larger micro-pores and higher surface roughness. The effects of applied anodic voltage on morphology and roughness of MAO coating can be interpreted by a single pulse energy model.

2. The apparent contact angle decreases slightly after treated at $80 \mathrm{~V}$, but it decreases sharply after treated at $160 \mathrm{~V}$ or $200 \mathrm{~V}$. The significant change in the apparent contact angle of MAO coatings may result from surface morphology and hydroxyl group content of the MAO coatings.

3. The wettability of the MAO coating prepared at lower voltages may be under-estimated due to smaller pores and lower hydroxyl group content. However, the wettability of the MAO coating prepared at higher voltages may be over-estimated due to no gas captured and coarser liquid/solid interface.

\section{Acknowledgments}

The authors acknowledge financial support provided by National Natural Science Foundation of China (Grant No. 51771119), Natural Science Foundation of Shanghai (Grant No. 17ZR1419600) and Project was supported by the Primary Research \& Developement Plan of Jiangsu Province (BE2017168).

\section{References}

1. Liu YJ, Li SJ, Wang HL, Hou WT, Hao YL, Yang R, et al. Microstructure, defects and mechanical behavior of beta-type titanium porous structures manufactured by electron beam melting and selective laser melting. Acta Mater. 2016;113:56-67.

2. Wu J, Guo R, Xu L, Lu Z, Cui Y, Yang R. Effect of Hot Isostatic Pressing Loading Route on Microstructure and Mechanical Properties of Powder Metallurgy Ti2AlNb Alloys. J Mater Sci Technol. 2017;33:172-8.

3. Mohazzab BF, Jaleh B, Kakuee O. Formation of titanium carbide on the titanium surface using laser ablation in n-heptane and investigating its corrosion resistance. Appl Surf Sci. 2019;478:623-35.

4. Bornstein MM, Valderrama P, Jones AA, Wilson TG, Seibl R, Cochran DL. Bone apposition around two different sandblasted and acid-etched titanium implant surfaces: a histomorphometric study in canine mandibles. Clin Oral Implants Res. 2008;19:23341.

5. Li D, Ferguson SJ, Beutler T, Cochran DL, Sittig C, Hirt HP, et al. Biomechanical comparison of the sandblasted and acid-etched and the machined and acid-etched titanium surface for dental implants. J Biomed Mater Res. 2002;60:325-32.

6. Ferguson SJ, Broggini N, Wieland M, Rupp F, Geis-Gerstorfer $\mathrm{J}$, Cochran DL, et al. Biomechanical evaluation of the interfacial strength of a chemically modified sandblasted and acid-etched titanium surface. J Biomed Mater Res. 2006;78:291-7.

7. Liu XM, Lim JY, Donahue HJ, Dhurjati R, Mastro AM, Vogler EA. Influence of substratum surface chemistry/energy and topography on the human fetal osteoblastic cell line hFOB 1.19: Phenotypic and genotypic responses observed in vitro. Biomater. 2007;28:4535-50.

8. Setzer B, Bachle M, Metzger MC, Kohal RJ. The gene-expression and phenotypic response of hFOB 1.19 osteoblasts to surfacemodified titanium and zirconia. Biomater. 2009;30:979-90.

9. Wang L, Xie L, Lv Y, Zhang LC, Chen L, Meng Q, et al. Microstructure evolution and superelastic behavior in Ti-35Nb$2 \mathrm{Ta}-3 \mathrm{Zr}$ alloy processed by friction stir processing. Acta Mater. 2017;131:499-510.

10. Wu J, Xu L, Lu ZG, Lu B, Cui YY, Yang R. Microstructure Design and Heat Response of Powder Metallurgy Ti2AlNb Alloys. J Mater Sci Technol. 2015;31:1251-7.

11. Huang P, Xu KW, Han Y. Hybrid process of micro-arc oxidation and hydrothermal treatment of titanium implant. J Porous Mater.2004;11:41-5. 
12. Xu J, Liu F, Luo J, Zhao LC. J Mater Sci Technol. Effects of Anodic Voltages on Microstructure and Properties of Plasma Electrolytic Oxidation Coatings on Biomedical NiTi Alloy. 2013;29:22-8.

13. Yang BC, Masaiki U, Kim HM, Zhang XD, Kokubo T. Preparation of bioactive titanium metal via anodic oxidation treatment. Biomater. 2004;25:1003-10.

14. Cui X, Kim HM, Kawashita M, Wang L, Xiong T, Kokubod $\mathrm{T}$, et al. Preparation of bioactive titania films on titanium metal via anodic oxidation. Dent Mater. 2009;25:80-6.

15. Yerokhin AL, Nie X, Leyland A, Matthews A, Dowey SJ. Plasma electrolysis for surface engineering. Surf Coat Tech. 1999;122:73-93.

16. Yerokhin AL, Snizhko LO, Gurevina NL, Leyland A, Pilkington A, Matthews A. Discharge Characterizationin Plasma Electrolytic Oxidation of Aluminum. J Phys D Appl Phys. 2003;36:2110-20.

17. Song YW, Dong KH, Shan DY, Han EH. Study of the formation process of titanium oxides containing micro arc oxidation film on Mg alloys. Appl Surf Sci. 2014;314:888-95.

18. Ma FC, Bo Z, Liu P, Li W, Liu XK, Chen XH, He DH, et al. Modeling of effects of thermomechanical processing on elevated-temperature mechanical properties of in situ (TiB + TiC)/Ti-1100 composite. J Mater Sci.. 2016;51:7502-11.

19. Yao Z, Jiang ZH, Sun XT, Xin SG, Li YP. Influences of current density on structure and corrosion resistance of ceramic coatings on Ti-6Al-4V alloy by micro-plasma oxidation. Thin Solid Films. 2004;468:120-4.

20. Cui WF, Jin L, Zhou L. Surface characteristics and electrochemical corrosion behavior of a pre-anodized microarc oxidation coating on titanium alloy. Mater Sci Eng C. 2013;33:3775-9.
21. Jones P, Hockey JA. Infra-red studies of rutile surfaces. Part 2.?Hydroxylation, hydration and structure of rutile surfaces. Trans Faraday Soc. 1971;67:2679-85.

22. Primet M, Pichat P, Mathieu MV. Infrared study of the surface of titanium dioxides. I. Hydroxyl groups. J Phys Chem. 1971;75:1216-20.

23. Wang JH, Wang J, Lu Y, Du MH, Han FZ. Effects of single pulse energy on the properties of ceramic coating prepared by micro-arc oxidation on Ti alloy. Appl Surf Sci. 2015;324:40513.

24. Lin Z, Liu K, Zhang YC, Yue XJ, Song GQ, Ba DC. The microstructure and wettability of the TiOx films synthesized by reactive DC magnetron sputtering. Mater Sci Eng B. 2009;156:79-83.

25. Yerokhin AL, Snizhko LO, Gurevina NL, Leyland A, Pilkington A, Matthews A. Discharge characterization in plasma electrolytic oxidation of aluminium. J Phys D Appl Phys. 2003;36:2110-20.

26. Li JM, Cai H, Xue XN, Jiang BL. The outward-inward growth behavior of microarc oxidation coatings in phosphate and silicate solution. Mater Lett. 2010;64:2102-4.

27. Whyman G, Bormashenko E, Stein T. The rigorous derivation of Young, Cassie-Baxter and Wenzel equations and the analysis of the contact angle hysteresis phenomenon. Chem Phys Lett. 2008;450:355-9.

28. Vivet L, Joudrier AL, Tan KL, Morelle JM, Etcheberry A, Chalumeau L. Influence of nickel-phosphorus surface roughness on wettability and pores formation in solder joints for high power electronic applications. Appl Surf Sci. 2013;287:13-21.

29. Wenzel RN. Resistance fo solid surfaces to wetting by water. Ind Eng Chem. 1936;28:988-94. 